\title{
Aluminum residue waste for possible utilisation as a material: a review
}

\author{
M SATISH REDDY ${ }^{1,2}$ and D NEERAJA ${ }^{1, *}$ \\ ${ }^{1}$ School of Civil and Chemical Engineering, Vellore Institute of Technology, Vellore 632014, India \\ ${ }^{2}$ Civil Engineering Department, Sreenivasa Institute of Technology and Management Studies, Chittoor 517127, \\ India \\ e-mail: 13phd0169@gmail.com
}

MS received 15 April 2016; revised 26 February 2018; accepted 8 March 2018; published online 30 June 2018

\begin{abstract}
Recycling and reutilization of industrial waste and by-products are subjects of great importance today in any sector and more so in cement and concrete technology. Aluminium is the most widely used nonferrous metal in the world. During the production of aluminum, a huge amount of waste is produced, known as dross, which is used for recycling and re-extraction of remaining aluminum. The dross is found to be toxic and hazardous waste for the environment and hence recycling or locking up of this waste is very crucial. The dross is mainly composed of oxides and aluminum and in the recycling, salt process is employed to recycle aluminum from the dross. This paper examines various forms of production of aluminum scrap, treatment methods, and typical application of aluminum residue. Brief description on waste management aspects is provided in this paper. The important observations made from the review studies are summarized.
\end{abstract}

Keywords. Aluminum waste; recycle; re-use; sustainability; treatment methods.

\section{Introduction}

In the present scenario, recycling and reutilization of industrial waste and by-products are of paramount importance in cement and concrete technology. Conventional industrial by-products used in cement and concrete production include fly ash, granulated blast furnace slag and silica fume. The reactivity and efficiency of these wastes as active additions were studied extensively [1-3]. Less reactive wastes are being used as supplementary cementitious materials in the manufacture of cement or inert aggregates in the production of mortar and concrete. Similarly, aluminium refining industries produce different solid wastes. Disposal and recycling of aluminium dross produced during aluminum melting is a global issue. Most of the dross is being disposed off in landfill sites, which results in leaching of toxic metal ions into ground water causing several pollution problems [4].

\section{Background information}

It is well known that aluminum dross is a by-product of aluminum production. Presently, more energy is consumed to recover aluminium from the dross. If the dross can be used as an engineering material through some process, energy could be saved. Further, if the dross is recycled for specific applications, some more energy can be saved. The main ingredients

*For correspondence of dross are $\mathrm{Al}, \mathrm{Al}_{2} \mathrm{O}_{3}, \mathrm{MgO}$ and $\mathrm{MgAl}_{2} \mathrm{O}_{4}$. However, due to the increasing awareness of ecological issues, the need for maximum economy and importance of recycling, the problem of dross removal is presently attracting more attention.

\subsection{White and black dross}

Drosses are generally classified in accordance with metal content into white and black dross. White dross contains larger quantity of aluminium content and it is produced from primary and secondary aluminium smelters. White dross contains from 15 to $70 \%$ recoverable metallic aluminium and it contains a fine powder from skimming the molten aluminium. For the case of black dross, it contains lesser metal content and is generated during aluminium recycling. Black dross consists of a mixture of aluminium oxides and slag, with recoverable aluminium content ranging between 12 and $18 \%$, and larger salt content i.e., higher than $40 \%$ compared to white dross. The term 'salt cake' signifies the non metallic residue obtained from dross smelting operations and generally contains $3-5 \%$ residual metallic aluminium [5]. It was reported in the literature $[6,7]$ that about four million tonnes of white dross and more than one million tonne of black dross is being produced every year and about $95 \%$ of this is landfilled. It was also reported that some portion of the dross is reprocessed by JBM International Ltd to recover metal aluminium and aluminium oxides. 
As the composition of aluminium dross is found to vary significantly from batch to batch, more focus is required to find potential applications for this material. Through cost effective recovery processes, aluminium metal can be recovered and aluminium oxides find applications in metallurgical and construction industry. In the literature, it was mentioned that the use of white or black dross as a filler in construction industry is significant. It was mentioned that the use of this dross (white/ black) as filler in asphalt may improve the stiffness, abrasion resistance and control of micro cracking. There are other potential applications of dross as various concrete products which require further value added information $[7,8]$.

\subsection{Scrap pretreatment}

Aluminum scrap comes from a variety of sources. "New" scrap is produced by pre-consumer sources, namely, (1) drilling and machining of aluminum castings, (2) aluminum fabrication and manufacturing operations, and (3) aluminum bearing residual material (dross) skimmed off molten aluminum during smelting operations. "Old" aluminum scrap is a material that was used by the consumer and discarded. For example; old scrap include (1) used appliances, (2) aluminum foil, (3) automobile and airplane parts, (4) aluminum siding, and (5) beverage cans. In scrap pretreatment, through sorting and processing scrap, contaminants are to be removed to prepare the material for smelting. By the method of sorting and processing, the aluminum from other metals, dirt, oil, plastics, and paint can be separated. Pretreatment cleaning processes are based on (1) mechanical, (2) pyrometallurgical, and (3) hydrometallurgical techniques (figure 1a).

As shown in figure $1 \mathrm{~b}$, smelting and refining is to be performed after scrap pretreatment. Both the process of smelting and refining for recovery of secondary aluminum takes place in reverberatory furnaces. These furnaces are constructed with brick-lined with a curved roof. The term reverberatory signifies that heat rising from ignited fuel is reflected back down from the curved furnace roof and later

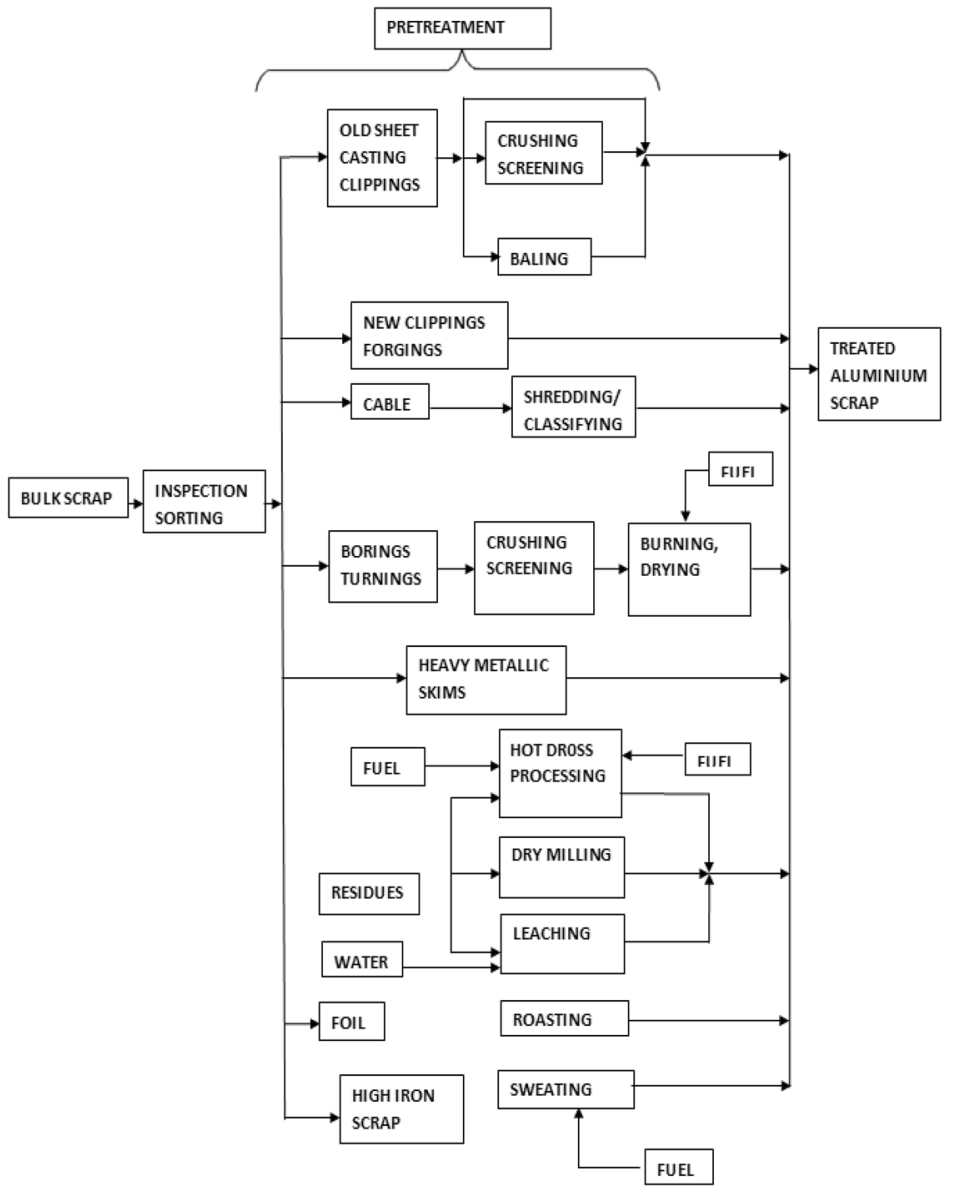

(a)

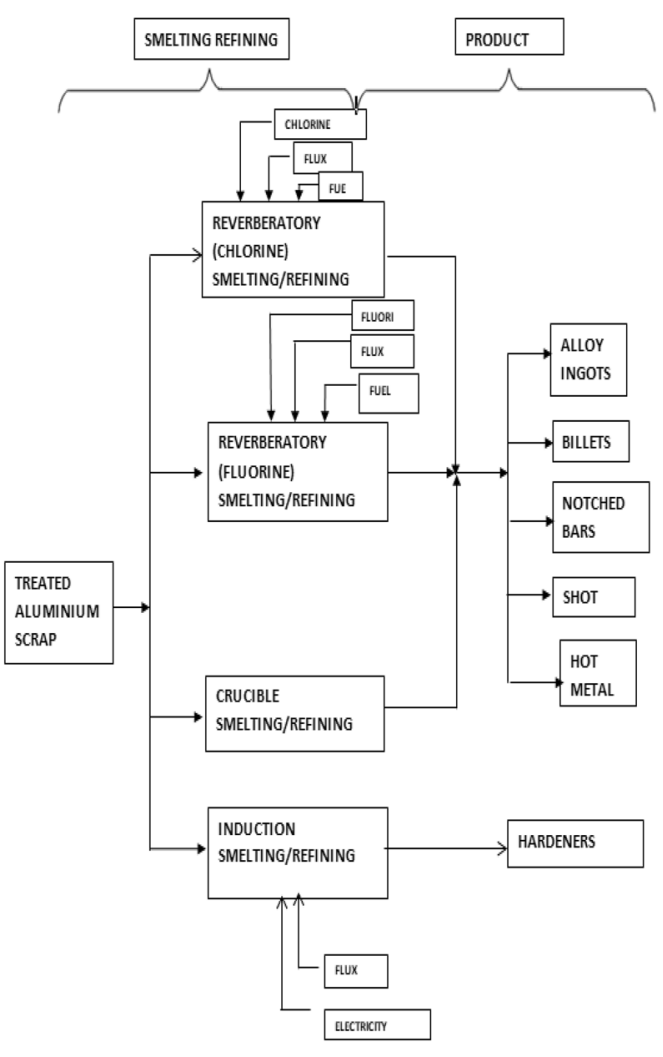

(b)

Figure 1. Typical process for secondary aluminum [20, 21]. 
into the melted charge. Smelting and refining process consists of several sequential steps, namely, (1) charging, (2) melting, (3) fluxing, (4) demagging, (5) degassing, (6) alloying, (7) skimming, and (8) pouring. The induction smelting and refining process is designed to produce aluminum alloys with enhanced strength and stiffness by blending aluminum and hardening agents in an electric induction furnace. The several processes include (1) charging scrap, (2) melting, (3) adding and blending the hardening agent, (4) skimming, (5) pouring, and (6) casting into notched bars. Hardening agents include manganese and silicon.

Conventionally, aluminum extraction was carried out through the rotary salt furnace (RSF) process. In this process, an oil or gas fired furnace is charged with the dross, and a salt flux up to $50 \%$ of dross weight is added. The salt protects the metal from the reactive atmosphere and facilitates agglomeration and separation of the metal, thereby metal recovery increases. Figure 2 presents the typical RSF process [9].

Saline slags are waste products, generated by melting process in a rotary furnace using saline fluxes. Saline slag composition depends on the quality and the composition of salt that was used. Saline slags generally contain 3-5\% metallic $\mathrm{Al}, 15-30 \% \quad \mathrm{Al}_{2} \mathrm{O}_{3}, 30-55 \% \mathrm{NaCl}, 15-30 \% \mathrm{KCl}$ and traces of $\mathrm{AIN}, \mathrm{AlC}_{3}$ and $\mathrm{Al}_{2} \mathrm{~S}_{3}$ [10]. Aluminium slags are generated through melting process in furnaces without fluxes. Aluminium slag composition vary significantly due to the generation of the same in different phases of the aluminium cycle. Aluminium dust is a waste product obtained through suction systems in aluminium manufacturing and transformation plants and from slag milling installations. It contains metallic aluminium, oxides, silicon oxides, nitrides, hydrides, silicon, $\mathrm{Zn}, \mathrm{Fe}, \mathrm{Pb}, \mathrm{Mg}, \mathrm{Cu}$, chlorides and fluorides.

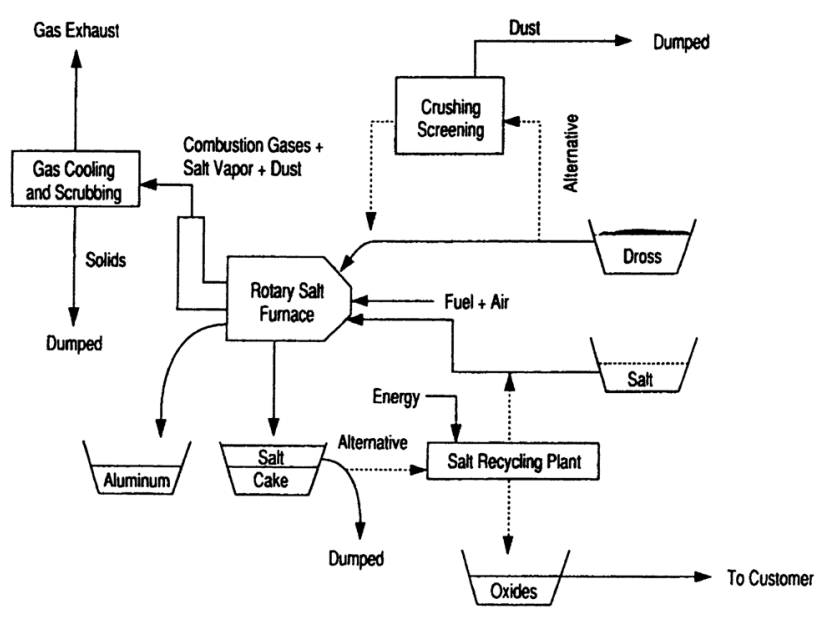

Figure 2. Typical process of the rotary salt furnace [9].

\subsection{Summary of treatment processes}

A new process of plasma heating technology proposed by Lavoie and Dube [11] for a salt-free treatment of aluminium dross found to reduce significantly the environmental issues. Physical and chemical properties of aluminium dross of granular and compact type were reported by Manfredi et al [12]. Various properties such as bulk density, salt content, particle size, composition, metal content were evaluated. Kevorkijan [13] reviewed the various experimental and analytical methodologies to evaluate the aluminium content of pressed dross. A relation between the bulk density, porosity and free aluminium content of pressed skulls was proposed. Tzonev and Lucheva [14] experimentally investigated aluminium by processing aluminium dross through direct-current electricarc rotary furnace. It was found from their studies that the recovery of aluminium is about $10 \%$ through this process. Adeosum et al [15] made refractory bricks by using aluminium dross waste and kaoline in different proportions. After evaluating the various properties such as the firing temperature, bulk density, thermal shock, permeability, loss on ignition, shatter index, shrinkage, porosity and thermal conductivity, it was found that the aluminium dross waste can be used in manufacture of refractory bricks.

In India, conservative estimates of the dross produced is 120,000 tons, based on dross produced from various sectors i.e., $1-2 \%$ from primary smelters, contaminated light section scrap $6-10 \%$ and from machine turnings such as unbaled, oxidized about $15 \%$. Table 1 presents the details of other treatment processes of aluminum waste.

\section{The comparison of the salt-free dross processing methods}

The technologies described above, are generally characterized under different operating conditions such as the furnace atmosphere, the nature of the heating source, hot or/and cold, the type of dross treated, the type of treatment vessel, the presence of cooling water, etc. Further, the technologies are also characterized by different metal recovery, composition of the treatment residues and treatment cost. The energy efficiency of air plasma is marginally higher than that of the nitrogen plasma. Since nitrogen is more expensive, air plasma is preferred and used in the ALCAN process. The energy efficiency is reported to be as high as 80-95\% [9]. Losses are in numerous ways, namely, through the walls, the stack, the door when open, and also in the torch cooling water. It is reported that using recoverable aluminum metal as a fuel to heat the furnace, is not economical and should be avoided if possible. Furthermore, in the plasma torch process, in order to remove the torch from the furnace for electrode maintenance needs highly specialized torch maintenance personnel [16]. The graphite arc technology proposed by Hydro-Quebec does not use 
Table 1. Various treatment processes of aluminum waste.

The Alcan plasma torch dross treatment process [9]

The Hydro-Quebec DROSCAR graphite arc process $[16,24]$

The ALUREC process [17, 24, 25]

The ECOCENT process [26, 27]

PyroGenesis DROSRITE process [28]
The Alcan plasma torch dross treatment process initially tested at Hydro-Quebec Research Center, in 1987, and is in operation at Alcan Treatment Center in Jonquieres, Canada. For additional heating a plasma torch was used in the rotary furnace. To control atmospheric conditions, the torch is placed on the charging door of the rotary furnace. Application of high voltage starts an electric arc between the torch electrodes after the dross is charged and the door is closed. The arc heats the gas to a very high temperature and the charge is heated to about $800^{\circ} \mathrm{C}$ while the furnace rotates. The aluminum available in the dross is finely divided and wrapped in oxide films. During heating of the dross, additional oxides and nitrides are formed due to the reaction of plasma gases with the free metal of dross. The oxide portion of the dross, termed as non-metallic product (NMP), grayish powder contains mostly alumina in variable quantities of aluminum nitride and magnesium oxide (figure 3)

Hydro-Quebec developed an innovative salt-free technology through a rotary furnace heated by a direct current electric arc between two graphite electrodes, called DROSCAR. Figure 4 shows the typical process of the entire dross treatment process. DROSCAR consists of a DC electric arc, stretched and maintained between the two graphite electrodes, to heat the charge above the aluminum melting point. The energy transfer mechanism is mainly radiation from the arc and conduction between the heated refractories and the charge. The rotation also prevents formation of hot spots on the charge or refractories, and improves energy transfer. On completion of heating, the metal is tapped from the furnace through a side tap hole. The solid residues present in the furnace form a grayish powder, is removed by tilting the furnace forwards while slowly rotating it An alternative electricity as the source of heat, focused on improving the fuel heated rotary furnace technology by using an oxygen-fuel burner and by controlling the atmosphere in the furnace to limit oxidation of the recoverable aluminum metal. Figure 5 presents a rotary tiltable converter type furnace, called ALUREC. From figure 5, it can be observed that the oxy-fuel burner and the exhaust gas port are located on the same side. It is mentioned that the improved design resulted in high-energy efficiency and controls the furnace atmosphere

A new process, named, "ECOCENT" is aluminum recycling process wherein some of the metal contained in the dross is recovered by centrifuging the hotdross as shown in figure 6 . This process is found to be an economical and ecologically sound. The advantages include (1) reduction of avoid exothermic losses, (2) intermediate storage and (3) unnecessary handling, (4) to save energy. In this process, the hot dross is fed without any fluxing salt additions into a converter where the relevant parameters for separation like temperature and viscosity can be adjusted. Further, large lumps of dross are crushed into smaller pieces in order to improve the later separation of the metal

Another salt-free dross processing technology, named as DROSRITE was developed by

Pyro-Genesis. With DROSRITE technology, hot dross is charged to a refractory-lined rotary furnace, immediately after skimming from the aluminum holding furnace

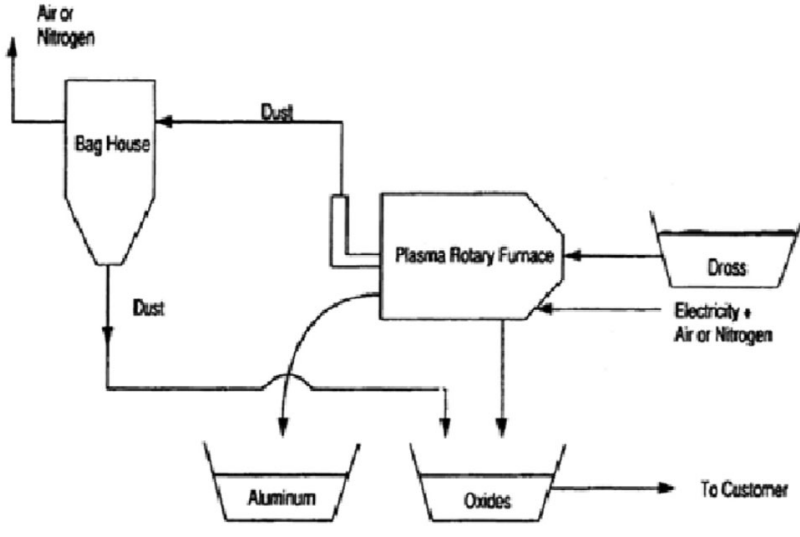

Figure 3. The flow sheet of the entire plasma dross treatment process. any cooling water and maintenance is not intensive as is the case for the plasma torch technology. Furthermore, gaseous and particulate emissions are significantly reduced with the DROSCAR technology. Argon is used especially for arc stabilization and its properties help to create an inert atmosphere inside the furnace, which significantly reduces any reaction between the molten aluminum and the furnace atmosphere.

The hazard created by possible water leaks over the molten metal can be eliminated by using the graphite arc and there is no water-cooled part in the DROSCAR furnace. In the DROSCAR, no metal combustion occurs. The average electrode consumption estimated at $0.91 \mathrm{~kg}$ per ton of dross. Since the DROSCAR process is operated under an inert atmosphere without salt addition, the residues are less 

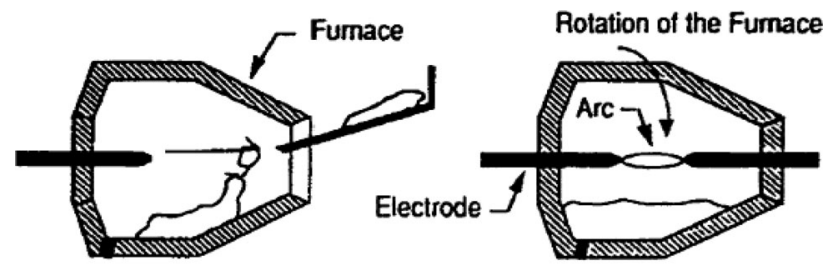

(a)

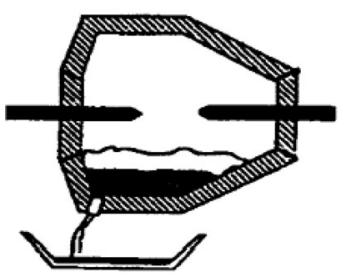

(c)

(b)

(d)

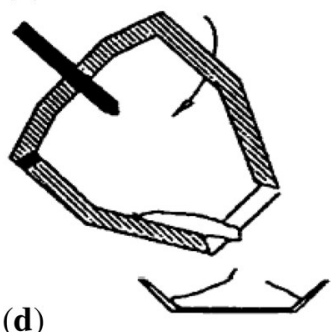

Figure 4. Typical phases of DROSCAR process [22, 23]. (a) Dross charging, (b) heating, (c) aluminum tapping and (d) discharging solid residues.

contaminated when compared to produced by an air plasma torch or a fuel burner [17]. In the ALUREC technology process, the exhaust gas from the oxy-fuel burner does not contain nitrogen. Exhaust gases of high concentrations of nitrogen can be produced with air-fuel burners and plasma burners. The presence of nitrogen in the flame provides a potential for the formation of aluminum nitrides that would contaminate the by-product from the process and could affect the aluminum yield.

Furthermore, the presence of nitrogen in the air plasma also promotes the formation of NOx, which is not the case with ALUREC where no nitrogen is used. The volume of exhaust gas from an oxy-fuel burner is little, about $25 \%$ of that of an air-fuel burner. This results in a smaller flame, and direct contact with the charge can be avoided. There will be less convection and less mass transfer between the oxy-fuel flame and the charge. Furthermore, the thermal efficiency of an oxy-fuel heated furnace is much higher due to the small exhaust gas volume. Considering the small exhaust gas volume, the exhaust gas composition and possibilities of accurately controlling this composition with oxy-fuel, it can be summarized that the aluminum oxidation in the process would be under control.

To prevent oxidation, RSF technique employs a salt flux and ALUREC uses atmosphere control [17] and therefore no salt addition is required. An efficient energy process can be realized in combination with the increased flame temperature. Compared with air-fuel, the energy consumption will be lower with oxy-fuel. The emissions of $\mathrm{CO}_{2}$ and $\mathrm{SO}_{2}$ will be reduced, since they are proportional to the fuel consumption. The formation of NOx is reduced because nitrogen is excluded from the combustion process. Depending on dross composition, about $500 \mathrm{~kg}$ of nonmetal product (NMP) is produced for every metric ton of dross. This is about half the amount of by-product compared with the RSF process.

\section{Alternate treatment processes}

Several alternate salt slag treatment processes such as freeze crystallization, solvent/antisolvent extraction, common-ion effect, high pressure/high-temperature process, and capillary-effect systems were proposed in the literature $[18,19]$. The process of "Freeze-Crystallization" involves cooling the solution beyond its saturation point. At the saturation point, the salts start to crystallize and precipitate out of the solution. Cooling continues until pure ice crystals start to form and rise to the surface, resulting in the precipitation of more salts. Using this method, it is possible to recover pure water and magnesium chloride from the solution in a reasonable purity. It is well known that recovering the magnesium chloride is highly desirable to prevent its build-up in the recycled flux as an impurity. The other process, namely, "Solvent/Antisolvent" was proposed as an alternative to evaporation. Firstly, the crushed salt cake will be leached with water at ambient temperature. Then, the residue, namely, aluminium oxide, in the leach effluent is washed off with water to remove residual salts. The clarified brine solution is concentrated to saturation using a forced-circulation evaporator. The saturated brine and recycle streams will be then fed to the antisolvent reactor with acetone by maintaining the acetone/water volume ratio of $1 / 1$. Another process, "Common Ion", was based on the concept of salting out the salt-cake salts from a saturated solution by the addition of compounds which contain chloride ions. The residual acidified solution will then be filtered to remove the precipitated salts and reconcentrated by removing some of its water content through boiling or freeze crystallization. Finally, "HighTemperature/High-Pressure Process" was based on leaching the salts at elevated temperatures using pressurized liquid water. By increasing the temperature from about $200-300^{\circ} \mathrm{C}$, the solubility of the sodium and potassium chlorides in liquid water will be increased by about 40 and $110 \%$, respectively. Hence, more salts could be leached at higher temperatures for every kilogram of water. The concept of leaching the salts at elevated temperatures may be integrated with more efficient separation methods, such as the freeze-crystallization processes.

\section{Various applications of solid waste from aluminum recycling process}

Table 2 highlights typical application of aluminium solid waste.

All the above applications mentioned in table 2 were carried out at small scale level. Some more studies are to be 
Table 2. Typical application of aluminum solid waste.
Shinzato and Hypolito Made concrete blocks by adding two parts of non-metallic product to one part of cement and four parts of sand. It was found that the blocks were qualified dimension, humidity and absorption tests but not compressive strength tests

Puertas [19]

Studied the physical and chemical interaction between a solid industrial waste from aluminium refining and saturated $\mathrm{Ca}(\mathrm{OH})_{2}$ solution, as well as the effects of substituting siliceous sand for the waste on the physical and mechanical properties of mortars. It was found that a decrease of the mechanical strengths and an increase of the total porosity

Pereira et al [10] Evaluated the mechanical properties of cement mortars by adding partial replacement of aluminum containing salt slags to either sand or cement. It was found that the both compression and flexural strengths decrease with increasing slag contents, irrespective of the curing period. Further, it was observed that up to $10 \%$ replacement, there is no significant decrease in strength

Das et al [29]

Martínez et al [30]

Domestic aluminium dross was treated for developing a suitable process flow sheet to obtain $\eta$-alumina which is a high valued product

Produced high-purity hydrogen gas from the chemical reaction of aluminum with sodium hydroxide. It was found that hydrogen yields are acceptable and purity was good enough to be used in a proton exchange membrane (PEM) fuel cell to produce electricity

Ozerkan et al [31] Investigated the mechanical and chemical properties of concrete made up of aluminium dross. The results indicated that aluminium dross can be used as an ingredient up to certain limits (up to $15 \%$ ) to improve expanded concrete/mortar and to enhance the corrosion resistivity of concrete/mortar. Due to the acceleration of setting times, this concrete may be used in buildings subfloors, panels and blocks

Adeosun [22]

Evaluated the physico-mechanical properties of aluminum dross in various percentages keeping amount of water as fixed. The bricks were made and studied the several aspects of volume shrinkage, apparent porosity, bulk density, cold crush strengths and permeability. From the investigation, it was found that the $106 \mu \mathrm{m}$ particle size brick can used as acid refractory because its properties compared well with medium-alumina fireclay

Badike and Osadebe Evaluated various properties such as density, Poisson's ratio, modulus of elasticity, modulus of rigidity of aluminum waste concrete. Aluminum waste was added in various proportions to concrete. From the overall studies, it was found that there is no significant change in the properties mentioned above compared to control concrete

Bajare et al [32] Found that non metal product (NMP) is suitable for production of expanded clay aggregates (ECA) with density ranging from 0.4 to $0.7 \mathrm{~g} / \mathrm{m}^{3}$. Mechanical properties of ECA are found to depend on the proportion of NMP and sintering temperature. Compression strength is found to be higher for ECA with fully developed pore structure

Bajare et al [33] New Porous Material was made from Industrial and Municipal Waste for Building Application. The material was characterized by density in the range $460-620 \mathrm{~kg} / \mathrm{m}^{3}$. Due to high porosity $(82-83 \%)$, the flexural strength was observed as $0.1 \mathrm{MPa}$ and the compressive strength was in the range of $1.1-2.3 \mathrm{MPa}$. The thermal conductivity of porous alkali activated specimens was found to be between 0.14 and $0.15(\mathrm{~W} /(\mathrm{m} \mathrm{K})$

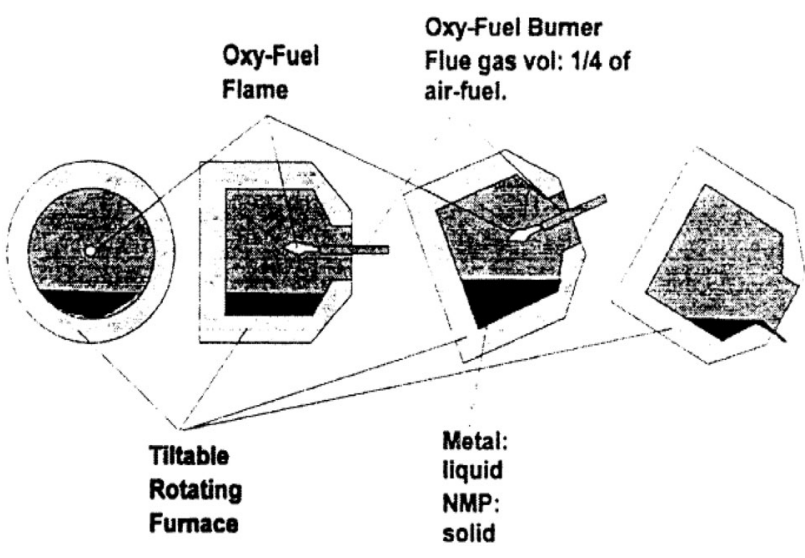

Figure 5. Typical ALUREC process.

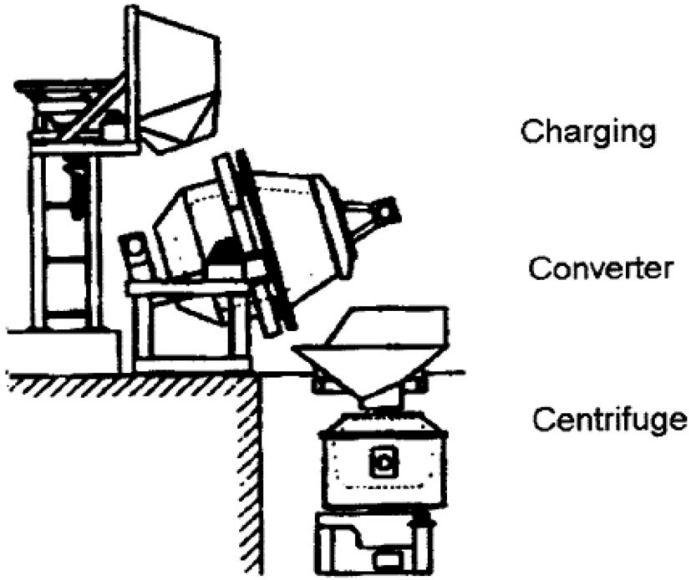

Figure 6. Typical ECOCENT process. 


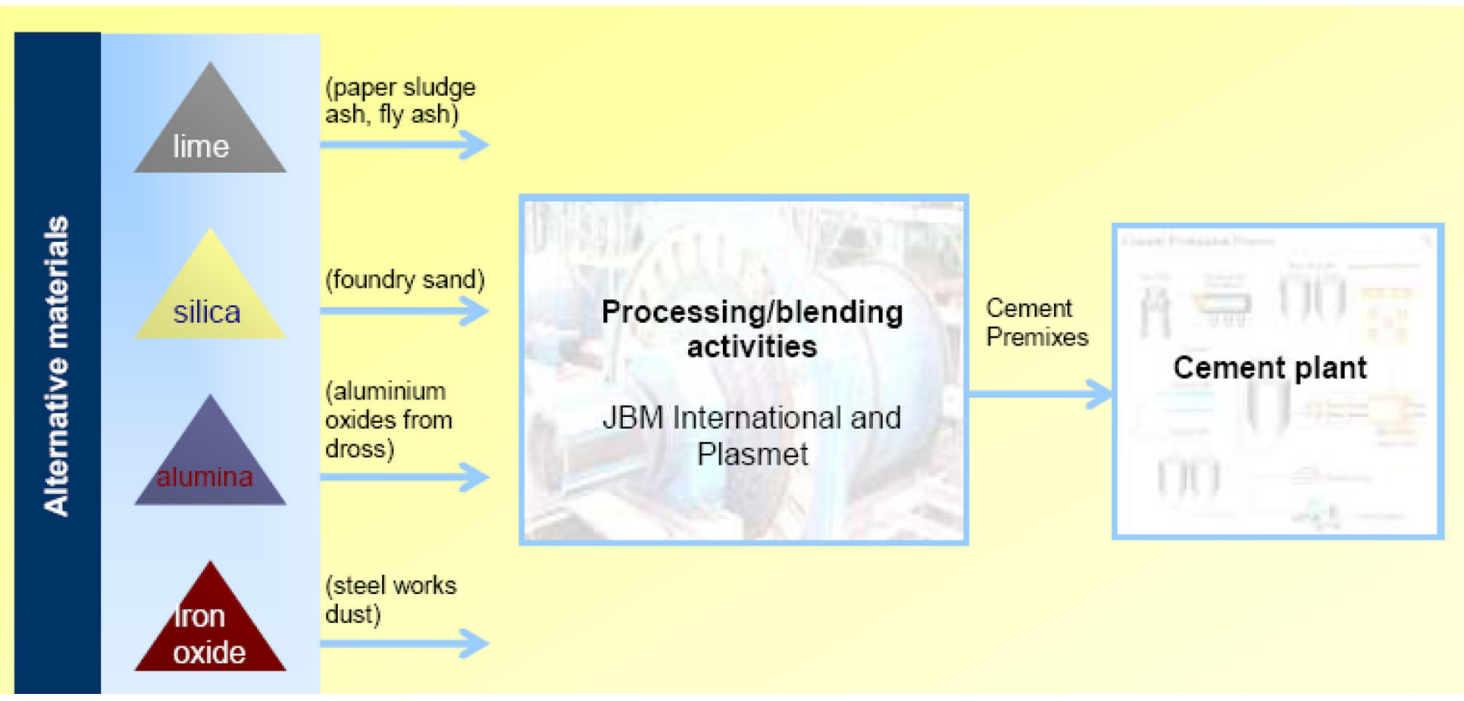

Figure 7. Use of alternative material including aluminium oxides for the production of feedstock for clinker production.

carried out to substantiate the findings before commercialization. Figure 7 shows the typical use of aluminium oxide for cement production.

Non-metallic residues produced during process of aluminium dross may be used as a source of aluminium oxide in cement/concrete related aspects.

The non metallic residue (NMR) can act as a source of alumina in ceramic and refractory applications. The applications include building bricks, pavers, firebricks. Other possible uses of NMR are shown below:

- Civil engineering field: as inert material for filling in concrete, pavements, mortar applications.

- Chemical industry: various applications include (1) production of hydrate aluminium oxide and aluminium salts, (2) epoxy resin mortar and (3) inert load in polymers.

- Metallurgical industry: synthetic steel refining slags to remove (1) sulphur, (2) phosphorus and (3) aluminium oxide from molten steel.

- Agriculture field: as artificial soil and fertilizer.

- Mineral wool.

\section{Summary and future directions}

- Dross is classified as toxic and hazardous waste (highly flammable, irritant, harmful and leachable), its landfill disposal is forbidden in most of the European countries and it should be recycled. Various dross treatment processes have been reviewed.

- Dross powders dispersed in aluminum alloy matrix via friction stir processing; the product found to be superior wear resistance with some sacrifice in strength. This certainly is a viable use of $\mathrm{Al}$ dross.

- The dross can be used as an additive to the slag to modify the chemistry.

Studies on possible utilization of aluminum dross as replacement of cement or fine aggregate are found to be less. Addition of dross to cement improves stiffness, abrasion resistance, and controlling micro-cracking of the material. There is an ample scope to carry out investigations on characterization studies and evaluation of mechanical and durability properties of aluminum waste for possible utilization as construction material.

\section{References}

[1] RILEM Technical Reports 1988 Siliceous by-products for use in concrete. Mater. Struct. 21(121): 69-80, 73-SBC RILEM Committee. Final report

[2] Metha P K 1989 Puzzolanic and cementitious by-products in concrete. In: Third Canmet/ACI Trondheim Conference: $1-43$

[3] Sersale R 1992 Advances in Portland and blended cements. IX Intern. Congr. Quim, Cem. 1: 262-302

[4] Unger T W and Beckmann M 1992 Salt slag processing for recycling, light metals. In: TMS Annual Meeting: 1159-1162, San Diego, California

[5] Hwang J Y, Huang X and Xu Z 2006 Recovery of metals from aluminium dross and salt cake. J. Miner. Mater. Charact. Eng. 5: 47-62

[6] Hollins O 2002 Aluminium industry could dramatically reduce landfilling of furnace waste. URL $<$ http://www.ohlsti. co.uk/ohl/newsletter/ohl_wmr312.pdf > . Accessed on 11 Nov 2007 
[7] Brough M 2002 Aluminium lightens the environmental load. In: Vision-The Newsletter of the Foresight and Link Initiative. Winter 2002. No 4. URL. Accessed on 11 Nov 2007

[8] Dunster A M, Moulinier F, Abbott B, Conroy A, Adams K and Widyatmoko D 2005 Added value of using new industrial waste streams as secondary aggregates in both concrete and asphalt. DTI/WRAP Aggregates Research Programme STBF 13/15C. The Waste and Resources Action Programme

[9] Lavoie S and Dube G 1991 A salt-free treatment of aluminium dross using plasma heating. J. Met. 2: 54-55

[10] Pereiraa D A, Barroso de Aguiarb, Castroc F, Almeidad M F and Labrinchae J A 2000 Mechanical behaviour of Portland cement mortars with incorporation of Al-containing salt slags, Cem. Concr. Res. 30: 1131-1138

[11] Lavoie S and Dube G 1991 A salt-free treatment of aluminium dross using plasma heating. J. Miner. Metals Mater. Soc. 43(2): 54-55

[12] Manfredi O, Wuth W and Bohlinger I 1997 Characterizing the physical and chemical properties of aluminium dross. $J$. Miner. Metals Mater. Soc. 49(11): 48-51

[13] Kevorkijan V 2002 Evaluating the aluminium content of pressed dross. J. Miner. Metals Mater. Soc. 54(2): 34-36

[14] Tzonev T Z and Lucheva B 2007 Recovering aluminum from aluminum dross in a DC electric-arc rotary furnace. J. Miner. Metals Mater. Soc. 59(11): 64-68

[15] Adeosun S O, Akpan E I and Dada M O 2014 Refractory characteristics of aluminium dross-Kaolin composite. $J$. Miner. Metals Mater. Soc. 66(11): 2253-2261

[16] Drouet M G, Handfield M, Meunier J and Laflamme C B 1994 Dross treatment in a rotary arc furnace with graphite electrode. J. Met. 5:26-27

[17] Gripenberg H, Grab H, Flesch G and Mullerthann M 1995 Alurec-a new salt-free process. In: Third International Symposium on Recycling of Metals and Engineered Materials. Miner Met \& Mater Society: 819-828

[18] Shinzato M C and Hypolito R 2005 Solid waste from aluminum recycling process: characterization and reuse of its economically valuable constituents, Waste Manage. 25: 37-46

[19] Puertas F, Blanco-Varela M T and Vazquez T 1999 Behaviour of cement mortars containing an industrial waste from aluminium refining stability in $\mathrm{Ca}(\mathrm{OH})_{2}$ solutions. Cem. Concr. Res. 29: 1673-1680

[20] Lopez-Delgado A, Tayibi H and Lopez F A 2007 Treatments of aluminium dust: a hazardous residue from secondary aluminium industry. In: Focus Hazard Mater Res: 1-52. New York, Nova Publishers
[21] https://www3.epa.gov/ttnchie1/ap42/ch12/final/c12s08.pdf

[22] Adeosun S O, Sekunowo O I, Taiwo O O, Ayoola W A and Machado A 2014 Physical and mechanical properties of aluminum dross. Adv. Mater. 3(2): 6-10

[23] Badike E M M and Osadebe N N 2014 The effect of aluminum waste on the material properties of concrete. Int. J. Comput. Eng. Res. 4: 17-22

[24] Drouet M G, Meunier J, Laflamme C B, Handfield M D, Biscaro A and Lemire C 1995 A rotary arc furnace for aluminium dross processing. In: Third International Symposium on Recycling of Metals and Engineered Materials. Miner. Met. \& Mater. Society: 803-812

[25] Gripenberg H, Mullerthann M and Jager N 1997 Salt-free dross processing with Alurec-two years experience. Light Met. 1171-1175

[26] Kos B 1997 A new concept for direct dross treatment by centrifuging of hot dross in compact type ecocent machines. Light Met. 1167-1169

[27] Kos B 2000 Secondary aluminium and recycling-direct dross treatment by centrifuging of hot dross. Alum. Dusseld. 76(1-2): 35-36

[28] Drouet M G, Leroy R L and Tsantrizos P G 2000 Drosrite salt-free processing of hot aluminium dross. TMS Fall Extraction and Process. Miner. Met. \& Mater. Society: 1135-1145. In: Metallurgy Meeting. Pittsburgh, Pennsylvania

[29] Das B R, Dash B, Tripathy B C, Bhattacharya I N and Das S C 2007 Production of $\eta$-alumina from waste aluminiumdross. Miner. Eng. 20: 252-258

[30] Martínez S S, Benítes W L, Gallegosa A A A and Sebastian J 2005 Recycling of aluminum to produce green energy. Sol. Energy Mat. Sol. C. 88: 237-243

[31] Ozerkan N G, Maki O L, Anayeh M W, Tangen S and Abdullah A M 2014 The effect of aluminium dross on mechanical and corrosion properties of concrete, Int. J. Innov. Res. Sci. Eng. Technol. 3(3): 9912-9922

[32] Bajare D, Korjakins A, Zakutajevs M and Voroneko F 2010 Applying of aluminium scrap recycling waste (non-metal product, NMP) for production environmental friendly building materials. In: 10th International Conference, Modern Building Materials Structures and Techniques: 13-17. Vilnus, Lithuania

[33] Bajare D, Bumanis G and Aleksandrskorjakins 2014 New porous material made from industrial and municipal waste for building application. Mater. Sci. 20(3): 333-337 